\title{
Burnout in the intensive care unit: it's a team problem
}

\author{
Jennifer Hancock, MD (i) - Richard Hall, MD, FRCPC • Gordon Flowerdew, ScD
}

Received: 29 July 2018/Revised: 29 November 2018/Accepted: 3 December 2018/Published online: 7 January 2019

(c) Canadian Anesthesiologists' Society 2019

\section{To the Editor,}

In 2016, the Critical Care Societies Collaborative published a call to action to raise awareness of burnout and its impact on critical care health professionals. ${ }^{1}$ In an effort to understand the magnitude of the issue at our institution, the Department of Critical Care Medicine, Dalhousie University, Nova Scotia completed a survey of its regional intensive care units (ICU) in January 2018. This included an academic adult, an academic pediatric, and a community adult ICU. Following approval from the Nova Scotia Health Authority Research Ethics Board (2017-12-08), surveys were distributed by email to 271 adult and pediatric ICU team members (166 nurses, 78 respiratory therapists, and 27 physicians). Survey design included participant demographics, the Maslach Burnout Inventory (MBI) - Human Services Survey for Medical Personnel $C^{2}$ and a question on moral distress. Moral distress occurs when, for a variety of reasons, an individual feels they cannot provide ethically appropriate care. Participants were provided with a definition of moral distress as well as examples of clinical situations and internal and external constraints, which may contribute to

J. Hancock, MD ( $\square)$

Department of Critical Care Medicine, Queen Elizabeth II Hospital, Dalhousie University, Halifax, NS, Canada

e-mail: jennifer.hancock@cdha.nshealth.ca

\section{R. Hall, MD, FRCPC}

Department of Critical Care, Department of Anesthesia, Pain Management \& Perioperative Medicine, Queen Elizabeth II Hospital, Dalhousie University, Halifax, NS, Canada

\section{G. Flowerdew, ScD}

Department of Community Health \& Epidemiology, Centre for Clinical Research, Dalhousie University, Halifax, NS, Canada this problem. Respondents rated the frequency of moral distress they experienced according to a seven-point Likert scale (ranging from never to everyday).

Table Level of burnout by Maslach Burnout Inventory domain and profession

\begin{tabular}{|c|c|c|c|c|c|}
\hline Burnout & $\begin{array}{l}\text { RT } \\
n=48\end{array}$ & \multicolumn{2}{|c|}{$\begin{array}{l}\text { RN } \\
n=93\end{array}$} & $\begin{array}{l}\text { MD } \\
n=24\end{array}$ & $\begin{array}{l}\text { Total } \\
n=165\end{array}$ \\
\hline \multicolumn{6}{|c|}{ Emotional exhaustion $n(\%)$} \\
\hline Low & $12(25)$ & \multicolumn{2}{|c|}{$31(33)$} & $12(50)$ & $55(33)$ \\
\hline Moderate & $23(48)$ & \multicolumn{2}{|c|}{$35(38)$} & $7(29)$ & $65(39)$ \\
\hline High & $13(27)$ & \multicolumn{2}{|c|}{$27(29)$} & $5(21)$ & $45(27)$ \\
\hline \multicolumn{6}{|c|}{ Depersonalization $n(\%)$} \\
\hline Low & $31(65)$ & \multicolumn{2}{|c|}{$45(48)$} & $11(46)$ & $87(53)$ \\
\hline Moderate & $12(25)$ & \multicolumn{2}{|c|}{$34(37)$} & $9(38)$ & $55(33)$ \\
\hline High & $5(10)$ & \multicolumn{2}{|c|}{$14(15)$} & $4(17)$ & $23(14)$ \\
\hline \multicolumn{6}{|c|}{ Personal accomplishment $n(\%)$} \\
\hline Low & $14(29)$ & \multicolumn{2}{|c|}{$29(31)$} & $3(13)$ & $46(28)$ \\
\hline Moderate & $20(42)$ & \multicolumn{2}{|c|}{$34(37)$} & 7 (29) & $61(37)$ \\
\hline High & $14(29)$ & \multicolumn{2}{|c|}{$30(32)$} & $14(58)$ & $58(35)$ \\
\hline \multicolumn{2}{|c|}{ Moral distress } & $\begin{array}{l}\text { RT } \\
n=43\end{array}$ & $\begin{array}{l}\text { RN } \\
n=87\end{array}$ & $\begin{array}{l}\text { MD } \\
n=24\end{array}$ & $\begin{array}{l}\text { Total } \\
n=154\end{array}$ \\
\hline \multicolumn{2}{|l|}{ None } & $0(0)$ & $0(0)$ & $0(0)$ & $0(0)$ \\
\hline \multicolumn{2}{|c|}{ A few times a year or less } & $14(33)$ & $22(25)$ & $10(42)$ & $46(30)$ \\
\hline \multicolumn{2}{|c|}{ Once a month or less } & $4(9)$ & $16(18)$ & $3(13)$ & $23(15)$ \\
\hline \multicolumn{2}{|c|}{ Few times a month } & $12(28)$ & $22(25)$ & $5(21)$ & $39(25)$ \\
\hline \multicolumn{2}{|l|}{ Once a week } & $4(9)$ & $12(14)$ & $4(17)$ & $20(13)$ \\
\hline \multicolumn{2}{|c|}{ A few times a week } & 8 (19) & $14(16)$ & $2(8)$ & $24(15)$ \\
\hline \multicolumn{2}{|l|}{ Every day } & $1(2)$ & $1(1)$ & $0(0)$ & $2(1)$ \\
\hline
\end{tabular}

$\mathrm{MD}=$ medical doctor; $\mathrm{RN}=$ registered nurse; $\mathrm{RT}=$ respiratory therapist 
One hundred and sixty-five $(60.9 \%)$ of the ICU healthcare providers completed the survey. Response rates varied between professional groups; from $89 \%$ among physicians to $56 \%$ among nurses. Symptoms of burnout were demonstrated in all of the MBI domains (Table). High levels of emotional exhaustion and a low sense of personal accomplishment were found in more than $25 \%$ of our respondents. Also, high levels of depersonalization were found in more than $10 \%$ of participants.

Moral distress was also a significant issue for our respondents (Table); $55.2 \%$ of participants reported moral distress at least a few times a month and $29.9 \%$ reported it at least once a week. Spearman correlation coefficients showed significant positive associations between moral distress and the burnout domains emotional exhaustion $(\mathrm{r}=$ $0.58, P<0.001)$ and depersonalization $(\mathrm{r}=0.34, P<$ 0.001 ), and a negative association with personal accomplishment $(\mathrm{r}=-0.16, P<0.05)$.

The rates of burnout reported in this cross-sectional survey are consistent with rates reported internationally and nationally ${ }^{1,3,4}$ and contribute to the limited published incidence of burnout in Canadian ICU. ${ }^{5}$ Our results reflect the experience of burnout in Halifax and cannot be generalized to the country as a whole. Nevertheless, our results suggest that, although rates may vary by profession, burnout is a problem for the team as a whole and may be prevalent across care providers. As we consider solutions, although some may be specific to the individual profession, it will be essential to consider interventions that are inclusive of the broader healthcare team.
Conflicts of interest None declared.

Editorial responsibility This submission was handled by Dr. Gregory L. Bryson, Deputy Editor-in-Chief, Canadian Journal of Anesthesia.

Funding Department of Critical Care Medicine, Halifax, NS, Canada.

\section{References}

1. Moss M, Good VS, Gozal D, Kleinpell R, Sessler CN. A Critical Care Societies collaborative statement: burnout syndrome in critical care healthcare professionals: a call for action. Am J Respir Crit Care Med 2016; 194: 106-13.

2. Maslach C, Jackson SE, Leiter M. MBI: Maslach Burnout Inventory. Palo Alto, CA: Consulting Psychologists Press; 1981.

3. Shanafelt TD, Hasan $O$, Dyrbye $L N$, et al. Changes in burnout and satisfaction with work-life balance in physicians and the general US working population between 2011 and 2014. Mayo Clin Proc 2015; 90: 1600-13.

4. Canadian Medical Association. CMA National Physician Health Survey: A National Snapshot - October 2018. Available from URL: https://www.cma.ca/Assets/assets-library/document/en/ advocacy/nph-survey-e.pdf (accessed December 2018).

5. Johnson-Coyle L, Opgenorth D, Bellows $M$, Dhaliwal $J$, Richardson-Carr S, Bagshaw SM. Moral distress and burnout among cardiovascular surgery intensive care unit healthcare professionals: a prospective cross-sectional survey. Can J Crit Care Nurs 2016; 27: 27-36.

Publisher's Note Springer Nature remains neutral with regard to jurisdictional claims in published maps and institutional affiliations. 